\title{
REU Site: Summer Undergraduate Research in Engineering/Science Pro- gram at the Georgia Institute of Technology
}

\author{
Dr. Leyla F Conrad, Georgia Institute of Technology
}

Dr. Leyla Conrad is the director of outreach in the School of Electrical and Computer Engineering (ECE) at the Georgia Institute of Technology. She has been developing and leading programs for ECE female and minority students, as well as high school students and teachers that supports the ECE's undergraduate recruitment and retention efforts. She is also the Education and Diversity Director of the NSF-funded Materials Research Science and Engineering Center at Georgia Tech. The Center's objective is to research fabrication and characterization approaches for the implementation of epitaxial graphene as an electronic material and to educate a diverse group of students at all levels in this field. Before her current appointment, she served as the education director of the NSF-supported research centers: Packaging Research Center from 1998 to 2006, and Center on Materials Devices for IT Research from 2006 to 2008. In both positions, she created and implemented a highly integrated and comprehensive educational program at all levels to meet the educational needs of pre-college, undergraduate, and graduate students, and industry engineers. Dr. Conrad received her Ph.D. degree in Physics from the University of Missouri - Columbia in 1990 .

\section{Dr. Gary S. May, Georgia Institute of Technology}

Dr. Gary S. May is the dean of the College of Engineering and professor of Electrical and Computer Engineering at the Georgia Institute of Technology. In that capacity, he serves as the chief academic officer of the college and provides leadership to over 400 faculty members and to more than 13,000 students. The College of Engineering at Georgia Tech is the largest producer of engineering graduates in the United States. In the most recent rankings by U.S. News \& World Report, Georgia Tech's engineering program ranked fourth. Prior to his current appointment, Dr. May was the Steve W. Chaddick School of Electrical and Computer Engineering chair at Georgia Tech. At the conclusion of his leadership in 2011, graduate programs in electrical engineering and computer engineering each ranked sixth, the computer engineering undergraduate program also ranked sixth, and the electrical engineering undergraduate program ranked fifth. All of these rankings represented the highest in the history of the school up to that point. Dr. May's field of research is computer-aided manufacturing of integrated circuits. He has authored over 200 technical publications, contributed to fifteen books, and holds a patent on that topic. He has also participated in the acquisition of over $\$ 49$ million in research funding, and he has graduated nineteen Ph.D. students. In 1993, Dr. May was named Georgia Tech's Outstanding Young Alumnus, and in 1999, he received Georgia Tech's Outstanding Service Award. Dr. May won international Best Paper Awards from IEEE Transactions on Semiconductor Manufacturing twice, in 1998 and 2000. In 2004, Dr. May received Georgia Tech's Outstanding Undergraduate Research Mentor Award, as well as the Outstanding Minority Engineer Award from the American Society of Engineering Education. In 2006, he received the Mentor Award from the American Association for the Advancement of Science (AAAS). In 2010, he was named the Outstanding Electrical Engineering Alumnus of the University of California at Berkeley. Dr. May is a fellow of AAAS and the IEEE. Dr. May created the Summer Undergraduate Research in Engineering/Science (SURE) program, for which he has been granted \$2.3 million from the National Science Foundation (NSF). Through SURE, he annually hosts minority students to perform research at Georgia Tech in the hopes that they will pursue a graduate degree. More than $73 \%$ of SURE participants enroll in graduate school. Dr. May is also the creator/director of the Facilitating Academic Careers in Engineering and Science (FACES) program, for which he has been granted over \$10 million from NSF to double the number of African American Ph.D. recipients produced by Georgia Tech. Over the duration of FACES, 373 minority students have received Ph.D. degrees in science or engineering at Georgia Tech the most in such fields in the nation. Dr. May is a member of the National Advisory Board of the National Society of Black Engineers. Dr. May received his B.S. in Electrical Engineering from Georgia Tech in 1985 and the M.S. and Ph.D. degrees in Electrical Engineering and Computer Science from the University of California at Berkeley in 1988 and 1991, respectively. 


\section{JillL L Auerbach, Georgia Institute of Technology}

Jill Auerbach is a senior academic professional in the School of Electrical and Computer Engineering at Georgia Institute of Technology. As the coordinator of assessment and student retention in the school, she is responsible for accreditation and program review requirements and assessment of several academic programs. In addition, Ms. Auerbach directs programs that promote student retention and success, especially among underrepresented, female and transfer student cohort groups. Her educational background is in the fields of Policy Analysis and Public Administration, with emphasis on research methodology. 


\title{
REU Site: Summer Undergraduate Research in Engineering/Science Program at the Georgia Institute of Technology
}

\begin{abstract}
The Summer Undergraduate Research in Engineering/Science (SURE) program, initiated in 1992, is a ten-week summer program for junior and senior level undergraduates from U.S. institutions. The overall goal of the program is to expose underrepresented students to engineering research, and as a direct consequence, interest them in opportunities available through graduate study. Participating students are paired with faculty and graduate student social mentors. During their stay, students attend weekly seminars on emerging research in engineering fields, enrichment and academic development activities, and social events. Students conclude the program with research presentations to their peers and faculty and graduate student mentors. During the past twenty years, 502 students participated in the program. These students were selected from a pool of 2,554 applicants. A comprehensive assessment program for SURE has been developed and implemented. The assessment process is driven by the overall program objective to provide participants a meaningful research experience and to increase the likelihood that participants will attend graduate school in engineering. This model identifies three cohorts from which data is collected. Each data source provides unique information that contributes to a comprehensive analysis of the impact and experiences of program participants and to an understanding of the academic trends of all SURE program applicants. The pre- and postprogram surveys include a series of questions about participants' perceived impact of SURE on planned graduate school attendance and research interests. The faculty advisor survey includes questions about the contribution the students made to their research programs, whether or not their student would succeed in graduate school, the quality of the students' oral and written project presentations, and how the program could be improved in future years. The Longitudinal Survey of Former SURE Participants addresses the primary objective of the SURE program to motivate participating students to attend graduate school in engineering. Respondents were asked a variety of questions about their academic decisions after participating in the SURE program. Detailed data about graduate school attendance, degree attainment, and major was collected. Questions were included to obtain feedback about their co-curricular activities and the environment of their undergraduate institutions. Another set of questions referred to sources of encouragement that students might have had when deciding to attend graduate school. Thus far, the program has been tremendously successful in attaining its objectives. It is shown that about $75 \%$ of the students who participate in the program attend graduate school after receiving their B.S. degrees.
\end{abstract}

\section{Introduction}

A key factor for motivating students to pursue advanced degrees and careers in science and engineering is a fruitful research experience as an undergraduate. Such experiences can be effective in helping students who exhibit uncertainty or a lack of confidence regarding attending graduate school. According to a study by SRI International [1,2], undergraduate research programs can be highly effective in helping students who are uncertain about going to graduate school to clarify their intent to pursue those goals and in bolstering the certainty of those students 
who have already decided to do so. Many minority students fit into these categories. While some are unsure whether to pursue graduate education at all, others want an advanced degree, but are uncertain about the other variables involved in this decision (i.e., what school to attend, M.S. versus MBA, etc.). Ultimately, the decision of the minority student to attend graduate school is profoundly affected by the amount of faculty involvement in their undergraduate career [3]. Quality interactions with faculty can have a significant impact on a student's decision to pursue graduate education, since such interaction provides the student with effective role models.

\section{Nature of Student Activities}

The overall goal of SURE is to expose students to research in engineering and science and as a direct consequence, interest them in opportunities available through graduate study. Students in the program receive subsidized on-campus housing for the duration of the program, a meal plan, a \$600 travel allowance, and full access to institutional facilities, including computer accounts, health care, recreational facilities, and the library. In addition, the participants are awarded a $\$ 5,000$ stipend. The financial incentives offered by SURE are designed to enable the recruitment of some of the best available students, many of whom choose to participate despite lucrative summer employment opportunities in industry.

SURE has assembled a dedicated and supportive cadre of faculty advisors who regularly involve undergraduate students in their research during the academic year and several of them have also served in that capacity in every summer as SURE faculty advisors. This group of very accomplished and diverse faculty advisors has proven to be excellent resources for SURE students because they share two viewpoints: (1) the importance of undergraduate research in encouraging graduate study; and (2) the need for all segments of society to participate in engineering and science careers. SURE ensures the development of interaction between the participants and the faculty by facilitating direct, one-on-one relationships. This enhances the research experience of the undergraduates by providing practical examples of the typical day-today interactions that take place between professors and graduate students [4]. In addition to faculty advisors, SURE students are also assigned graduate student research mentors. Pairing undergraduate students with graduate students closer to their peer group eases student communication and helps alleviate any discomfort that the undergraduates might feel as they acclimate themselves to the research environment [5]. In order to provide a cohesive research experience, graduate mentors are advisees of the faculty. In this way, mentors are capable of dealing with the students' day-to-day questions and concerns related to general aspects of campus and community life. Furthermore, every SURE student is also paired with an additional graduate student mentor. These mentors are selected among minority engineering and science graduate students who are actively involved in NSBE, LOGRAS, SPHE, and Office of Minority Education and Development outreach programs. Mentor matching is based upon evaluation of a list that includes the student participant's home school, hometown, research area, and faculty advisor. A maximum of two and a minimum of one SURE participant(s) are assigned to each mentor.

Student communication and skill development are enhanced by several group activities such as seminars, workshops and field trips. Students broaden their knowledge and become better 
acquainted with research through weekly technical seminars on state-of-the-art topics. The seminars that were offered during 2012 are provided in Table 1.

Table 1: The 2012 SURE Seminar Series

\begin{tabular}{|l|l|l|}
\hline Date & Topic & Speaker \\
\hline \hline Week 1 & "Renewable Fuels from Biomass" & Dr. Carsten Sievers \\
\hline Week 2 & "The Origin of Life" & Dr. Loren Williams \\
\hline Week 3 & $\begin{array}{l}\text { "Importance of Interdisciplinary Engineering Research: } \\
\text { A Case Study for Fluid-Structure Interaction" }\end{array}$ & Dr. Marilyn Smith \\
\hline Week 4 & $\begin{array}{l}\text { "Bad blood flow causes atherosclerosis - From } \\
\text { discovery of mechanosensitive genes to development of } \\
\text { therapeutics" }\end{array}$ & Dr. Hanjoong Jo \\
\hline Week 5 & $\begin{array}{l}\text { "The Extreme Danger of Computers in Engineering } \\
\text { Practice" }\end{array}$ & Dr. Leroy Z. Emkin \\
\hline Week 6 & "Challenges in Flightdeck Design" & Dr. Amy Pritchett \\
\hline Week 7 & $\begin{array}{l}\text { "Putting Nanomaterials to Work for Biomedical } \\
\text { Research" }\end{array}$ & Dr. Younan Xia \\
\hline Weei 8 & "Applying to Graduate School" & Dr. Jeffrey Donnell \\
\hline Week 9 & "The Problems with Interconnect" & Dr. Paul Kohl \\
\hline Week 10 & End of Program Project Presentations & Participants \\
\hline
\end{tabular}

Meetings are held every Tuesday morning where each participant reports orally what he/she has accomplished in the past week and his/her plans for the current week. Following the individual research status reports, fundamental research skills are taught to participants through interactive exercises to better prepare them for a successful research experience. Topics that were covered last summer are provided in Table 2. In addition to graduate school related subjects, three fundamental areas - communication, investigation and documentation - are emphasized in the workshops [6-8]. Participants complete the online Responsible Conduct of Research (RCR) course available for students and postdocs at the Collaborative Institutional Training Initiative site, www.citiprogram.org. All the participating students also receive two sessions each of threehour in-class GRE preparation.

Table 2: 2012 SURE Weekly Research Workshops

\begin{tabular}{|l|l|l|}
\hline Date & Topic & Speaker \\
\hline \hline Week 1 & $\begin{array}{l}\text { Research Methods Orientation and Literature Review } \\
{[9,10]}\end{array}$ & Dr. Tom Gaylord \\
\hline Week 2 & Public Speaking and Goal Definitions & SURE Coordinator \\
\hline Week 3 & The Graduate School Search & SURE Coordinator \\
\hline Week 4 & Finding the Right Thesis Advisor & SURE Coordinator \\
\hline Week 5 & $\begin{array}{l}\text { Ph.D Considerations: Qualifiers (Prelims), Proposals and } \\
\text { Dissertation }\end{array}$ & SURE Coordinator \\
\hline \multirow{3}{*}{ Week 6 } & Turning your SURE Summer Research ino a Publication & SURE Coordinator \\
\cline { 2 - 3 } & GRE Prep Course I & $\begin{array}{l}\text { Princeton Review } \\
\text { Instructor }\end{array}$ \\
\cline { 2 - 3 } & GRE Prep Course II & Princeton Review \\
\hline
\end{tabular}




\begin{tabular}{|l|l|l|}
\cline { 2 - 3 } \multicolumn{1}{c|}{} & & Instructor \\
\hline Week 7 & Life of a Graduate Student & Graduate Student Panel \\
\hline Week 8 & Giving Effective Presentations & Dr. Lisa Rosenstein \\
\hline Week 9 & The Elevator Talk and Networking [11] & SURE Coordinator \\
\hline Week 10 & Show Me The Money: Funding for Graduate School & Dr. Karen Adams \\
\hline
\end{tabular}

Participants tour at least two industry sites during their stay. Sites that have been visited in the past three years include Georgia Power, Lockheed-Martin, and Cisco. A working relationship has been established with these companies' outreach and community relations teams, and they provide an overview presentation followed by 3-4 hours long tour. A group photo taken last summer by the Lockheed-Martin photographer is shown in Fig. 1.

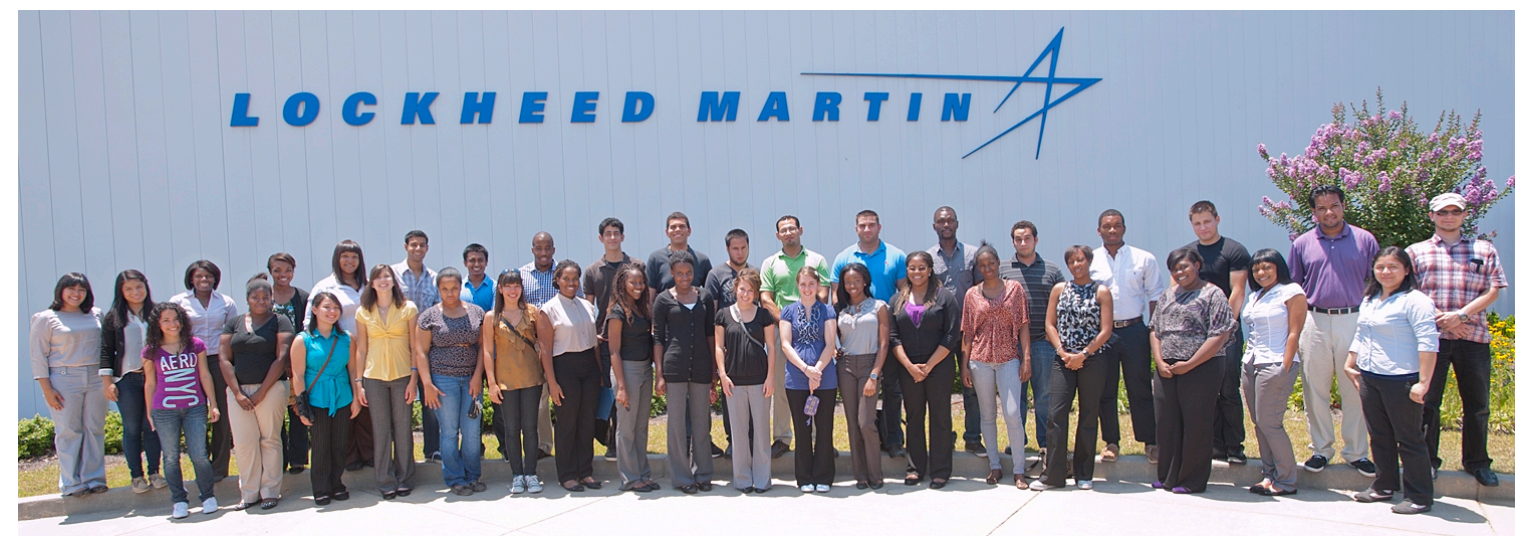

Figure 1 - SURE 2012 participants at the Lockheed-Martin plant located at Marietta, GA

The social and collegial development of the SURE participants is encouraged and facilitated by group cultural outings such as trips to museums, plays, athletic events, the Georgia Aquarium, Six Flags or concerts taking place in the Atlanta area.

\section{Student Recruitment and Selection}

The SURE program is advertised electronically via its own Internet home page (http://www.sure.gatech.edu). General program information, as well as an on-line application, is available at this site. The program is also listed on the NSF and the Institute for Broadening Participation web sites. In addition to these, students are recruited by announcements and advertisement through several national engineering organizations, including the National Society of Black Engineers (NSBE) and the Society of Hispanic Professional Engineers (SHPE). The SURE program receives $180-230$ applications every year. More than $90 \%$ of applications come from students attending higher education institutions other than the home institution, and quite a large portion of them from undergraduate institutions and two-year colleges where research opportunities for undergraduates are typically less available. Recruitment takes place during October through February of each year, and student applications are due March 1. Criteria for selection consist of the student's academic record (GPA, transcript, and academic honors), a statement of interests, and one letter of recommendation from a faculty member at the student's home institution. Applications are evaluated by a committee of faculty advisors participating in the program to assure optimal matching of student skills and interests to research projects. 
Alternates are selected in the event that any of the initial candidates decline the invitation to participate.

Tables 3 and 4 provide the demographic profile of SURE applicants and participants in the past twenty years, from 1992-2012. Since its inception, a total of 502 students have participated in the SURE program.

Table 3: Applicant/Participant Ethnicity from 1992-2012

\begin{tabular}{|l|l|l|}
\hline Ethnicity & Applied & Selected \\
\hline \hline $\begin{array}{l}\text { African } \\
\text { American }\end{array}$ & $\begin{array}{l}1815 \\
(71 \%)\end{array}$ & $371(76.3 \%)$ \\
\hline $\begin{array}{l}\text { Hispanic } \\
\text { American }\end{array}$ & $334(13 \%)$ & $88(15.9 \%)$ \\
\hline Native American & $4(0 \%)$ & $1(0.2 \%)$ \\
\hline Other & $401(16 \%)$ & $42(7.5 \%)$ \\
\hline TOTAL & 2,554 & 502 \\
\hline
\end{tabular}

Table 4: Applicant/Participant Gender from 1992-2012

\begin{tabular}{|l|l|l|}
\hline Gender & Applied & Selected \\
\hline \hline Male & $1388(54 \%)$ & $299(60 \%)$ \\
\hline Female & $1134(44 \%)$ & $203(40 \%)$ \\
\hline Not known & $32(2 \%)$ & \\
\hline TOTAL & 2,554 & 502 \\
\hline
\end{tabular}

\section{Program Evaluation}

The assessment process is driven by the overall program objective to provide participants a meaningful research experience and to increase the likelihood that participants will attend graduate school in engineering. This model identifies three cohorts from which data is collected. Each data source provides unique information that contributes to a comprehensive analysis of the impact and experiences of program participants and to an understanding of the academic trends of all SURE program applicants. A brief overview of the data sources, assessment goals, and collection methods for annual evaluation and participant tracking are as follows:

1. An annual "SURE Participant Pre-program Survey" is distributed on the first day of the program at the orientation to determine program expectations, undergraduate research experiences, and attitudes towards graduate school attendance.

2. An annual "SURE Participant Focus Group Session" is administered midway to determine if the REU program is progressing satisfactorily and as planned.

3. An annual "SURE Participant Post-program Survey" is distributed on the last day of the SURE program to assess the quality of program components, extent expectations were met, and initial reactions to likelihood of graduate school attendance.

4. An annual "Faculty Advisor Post-program Survey" is electronically distributed at the end of the program to measure the contribution that students made to their research programs, evaluate the quality of the students' oral and written project presentations, plans for future student-mentor interaction and provide any recommendation for program improvement. 
5. A "Longitudinal Survey of Former SURE Program Participants" that uses multiple distribution methods in order to maximize response rate and to track stability of academic field, graduate school attendance/degree completion, research activities, and their impressions on how the program helped them, and any suggested improvements to the program. This survey was administered for the first time in 2005 and then in 2009.

The pre- and post-program surveys include a series of questions about participants' perceived impact of SURE on planned graduate school attendance and research interests. Using a Likert response scale, students rank the perceived level of impact. The response categories for the program effectiveness questions ask respondents to rate various program components on a 4point quality scale and students are asked to answer questions about the appropriate number of program activities.

Pre-program Evaluation: The pre-program survey is administered on the first day of the program. Highlights from the past three year pre-program survey findings indicated that the participants' primary reason for attending the SURE program was to learn new skills (78\%), followed by the pursuit of their particular research interest (62\%). Other reasons for attending the SURE program include the desire to learn more about attending graduate school at the host institution (54\%) and 51\% said SURE would enhance their resume for career purposes. When asked about the importance of the various SURE program components, participants indicate that having exposure to Georgia Tech research faculty $(84 \%)$ and working at Georgia Tech research facilities (69\%) are extremely important.

Post-program Evaluation: The post-program survey is administered on the last day of the program. It measures perceptions of gains from the SURE experience in different areas, including gains in personal growth and research-related skills and knowledge. According to the findings of the past three years of post-program surveys, SURE participants reported significant gains in:

i. Understanding what everyday research is like (71\%)

ii. Planning and preparing for graduate school (64\%)

iii. Understanding the theory and concepts that guided their research (64\%)

iv. Confidence in their ability to do well in future technical/scientific courses $(59 \%)$

v. Identifying limitations of research methods and designs (56\%)

vi. Using problem solving skills in the research process

Other highlights from the post-program surveys include the noteworthy finding that $80 \%$ of the participants indicated that SURE experience increased their desire to attend graduate school compared to $13 \%$ who said that the experience had no impact either way and $7 \%$ who said it lessened their desire to attend graduate school. An overall measure of satisfaction with the experience is evidenced by the $91 \%$ who said they would strongly recommend SURE to other students. When asked if the SURE experience enhanced their understanding of graduate student life, $65 \%$ said significantly enhanced understanding and $31 \%$ indicated moderate enhancement. This finding is important because of the need to expose students to the environment and demands of graduate school life. The above data indicates that SURE has been a resounding success in meeting the primary objectives of the program. 
Faculty Advisor Feedback: The SURE faculty survey is administered to the faculty advisors within two weeks of the end of the program. According to survey responses from the past three years, a majority of faculty advisors rated the quality of their SURE students "excellent" on the following attributes: willingness to work on the assigned project (83\%), ability to fit in at the lab $(67 \%)$ and motivation to learn about research (69\%). Eighty-three percent of the faculty said they would provide a recommendation for the student's graduate school application. In addition, faculty advisors were eager to keep in touch with SURE students and planned to contact them in the coming year for any of the following reasons:

i. Follow-up for any unfinished business related to the summer research project (39\%)

ii. Discuss future plans for student to continue working on summer research project $(43 \%)$

iii. Discuss future opportunities for student to work on a different research project $(20 \%)$

iv. Discuss graduate schools procedures, opportunities or program choices $(40 \%)$

v. Follow-up with student for no specific reason $(26 \%)$

Finally, SURE faculty advisors are asked to comment on the contribution which the students made to their research programs, speculate as to whether or not their student would succeed in graduate school, evaluate the quality of the students' oral and written project presentations, and give a recommendation as to how the program could be improved in future years.

\section{Participant Tracking}

The Longitudinal Survey of Former SURE Participants addresses the primary objective of the SURE program to motivate participating students to attend graduate school in engineering. The study was conducted in 2005 on the population of students who were participants in the 19992003 SURE programs, and then in 2009 on the 2003-2007 participants. Thus, all respondents had been out of the SURE program for at least two years. Most participants were rising juniors or seniors at the time they were in the SURE program, thus, two years is a reasonable interlude to provide students time to complete their baccalaureate studies and enter a graduate program. However, the 2003 participants who were still pursuing their B.S. degrees during the 2005 implementation were contacted again in 2009.

Respondents were asked a variety of questions about their academic decisions after participating in the SURE program. Detailed data about graduate school attendance, degree attainment, and major was collected. Questions were included to obtain feedback about their co-curricular activities and the environment of their undergraduate institutions. Another set of questions referred to sources of encouragement that students might have had when deciding to attend graduate school. Finally, a series of questions that asked about specific experiences during SURE were included $[12,13]$. The foundation of this approach was to determine if SURE participants subsequently chose to attend graduate programs of study and what factors may be associated with this decision specifically:

- Do co-curricular activities at the students' home institutions - such as membership in professional organizations, co-op participation, or other undergraduate research 
activities - play a role in graduate school attendance?

- What are the influences of students' peers and family on the decision to attend graduate school?

- What role did the SURE program in general play in the decision to attend graduate school?

- What effect does the mentoring provided by the SURE program have on the decision to attend graduate school?

The response rate to the survey was $58.7 \%$ in 2005 and $65.2 \%$ in 2009 . A total of 71 responses were obtained in 2005, of which 62 had completed baccalaureate programs of study. Similarly, a total of 88 responses were obtained in 2009, of which 86 had completed baccalaureate programs of study. Basic demographic and academic characteristics of these respondents who had completed their B.S. degrees since participating in the SURE program are presented in Table 5.

Table 5: Respondents' Demographic and Academic Data

\begin{tabular}{|l|l|l|}
\hline & $\begin{array}{l}\text { \%of Respondents } \\
\text { (2005 Study) }\end{array}$ & $\begin{array}{l}\text { \% of Respondents } \\
\text { (2009 Study) }\end{array}$ \\
\hline Male & 52 & 60 \\
\hline Female & 48 & 40 \\
\hline African American & Data not available & 76 \\
\hline Hispanic American & Data not available & 15 \\
\hline Other (White or Asian) & Data not available & 9 \\
\hline Type of Undergraduate Institution & & \\
\hline Minority Serving Instituion & 45 & 27 \\
\hline Research/Doctoral & 56 & 67 \\
\hline Master's & 17 & 8 \\
\hline Baccalaureate & 14 & 14 \\
\hline Dual Degree Program & 13 & 8 \\
\hline Undergraduate Major & & \\
\hline Science & 29 & 14 \\
\hline Engineering & 71 & 86 \\
\hline Graduate School Status & & 6 \\
\hline Completed Ph.D. Degree & 0 & 34 \\
\hline Enrolled in Ph.D. Program & 34 & 20 \\
\hline Terminal Masters Degree & 15 & 16 \\
\hline Enrolled in Masters Program & 24 & 24 \\
\hline $\begin{array}{l}\text { Completed B.S. Degree and did not Enroll } \\
\text { in Any Graduate Program }\end{array}$ & 27 & 76 \\
\hline Went to Graduate School & 73 & \\
\hline
\end{tabular}

The two most noteworthy results are:

1. 73-76\% of the students who participated in the program during 1999-2007 and responded to the survey went to graduate school.

2. $\mathbf{3 4 - 4 0 \%}$ of the students who participated in the program during 1999-2007 and 
responded to the survey were enrolled in a Ph.D. program or received a Ph.D. degree at the time of the study.

These figures are extremely high when compared to the nationwide low graduate enrollment of minority students in engineering [2]. Therefore, this is a significant accomplishment for the SURE program. Furthermore, of the students who were enrolled in a Ph.D. program, half of them attended graduate school at Georgia Tech. This shows that the SURE program also acts as an effective graduate recruitment activity.

Based on the survey findings, SURE students who attended graduate school reported more frequent encouragement from family and friends compared to their non-graduate school counterparts. An interesting finding is the apparent influence of the SURE program on participants' consideration of graduate school. While $49 \%$ of the 2009 respondents agreed that they were interested in attending graduate school before their SURE experience, $77 \%$ were interested after the experience. Thus, the experience of the program reinforces the choice to attend graduate school among those predisposed to do so and also attracts those who were previously not interested. In addition, it would appear that regardless of whether or not the respondent eventually attended graduate school, participants agreed that the SURE experience was beneficial to their careers $-93.3 \%$ of graduate school attendees, and $88.2 \%$ of nonattendees. This suggests that even though participation in the SURE program contributes to the increase of graduate enrollment, participants find the experience helpful to their future careers regardless of whether they attend graduate school.

\section{Conclusion}

The SURE program that has existed since the summer of 1992 and funded by the NSF REU program has been designed to expose qualified minority and female students to engineering/science research at the host site. Students, who are paired with both a faculty advisor and graduate student mentor, undertake meaningful research projects, visit local industry, and attend weekly seminars and skill development workshops. Thus far, the program has been tremendously successful in attaining its objectives. It has been shown that about $75 \%$ of the students who participated in the program attended graduate school upon receiving their B.S. degrees. Although underrepresented minorities only account for a very low overall percentage of advanced degree recipients in engineering, over the past decade, the number of advanced degrees awarded to persons in these segments of the population has increased [14]. SURE and programs like it have played a pivotal role in this trend.

\section{Acknowledgements}

The authors would like to express their gratitude to the National Science Foundation (award number EEC-0851643) for supporting the SURE program.

\section{Bibliography}


1. S. Russell, "Evaluation of NSF Support for Undergraduate Research Opportunities," Draft Synthesis Report, SRI Project Number P16346, July, 2006.

2. S.H. Russell, M.P. Hancock, and M. McCullough, "The Pipeline: Benefits of Undergraduate Research Experiences," Science, vol. 316, pp. 548-549, April, 2007.

3. V. Tinto, "Dropout from Higher Education: A Theoretical Synthesis of Recent Research," Review of Educational Research, vol. 45, no. 1, 1975.

4. E. Barnes, "Getting Minorities into Ph.D. Pipeline Requires Active and Early Intervention, Say Experts," Black Issues in Higher Education, July, 1992.

5. J. Fairley, L. Conrad, and G. May, "The Importance of Graduate Mentors in Undergraduate Research Programs," Proc. 2007 ASEE Conference and Exposition, Honolulu, HI, June, 2007.

6. D.J. Lilja, "Suggestions for Teaching the Engineering Research Process", Proc. 1997 ASEE Conference and Exposition.

7. J. Fairley, J. Auerbach, A. Prysock, L. Conrad, G. May, "Teaching Research Skills in Summer Undergraduate Research Programs", Proc. American Society for Engineering Education 115th Annual ASEE Conference \& Exposition, Pittsburgh, PA, 2008.

8. Ashley N. Johnson, Jill Auerbach, Adrianne Prysock, Leyla Conrad and Gary S. May, "Development and Implementation of Academic Enrichment Activities for REU Students," Proc. 2009 ASEE Conference and Exposition, San Antonio, TX, June 2009.

9. D. Taylor and M. Procter, "The Literature Review: A Few Tips On Conducting It", Writing Support, J. Plotnick, Editor. University of Toronto Toronto. 2007.

10. G. Stacks and E. Karper, The Online Writing Lab at Purdue University. 2001, Purdue University: Lafayette.

11. G. Duncan, "How to make your 'elevator talk' a floor above the rest", The Denver Business Journal 2005: Denver.

12. R. Morley, J. Havick, and G. May, "An Evaluation of the Georgia Tech Summer Undergraduate Program of Research in Electrical Engineering for Minorities," J. Eng. Education, vol. 87, no. 3, July, 1998.

13. J. Auerbach, C. Davis, J. Gordon, and G. May, "A Comprehensive Examination of the Impact of the Summer Undergraduate Research Program on Minority Enrollment in Graduate School," Proc. 2007 ASEE Conference and Exposition, Honolulu, HI, June, 2007.

14. Women, Minorities, and Persons with Disabilities in Science and Engineering: 2011 www.nsf.gov/statistics/wmpd/ 